\title{
Vitamin C (Ascorbic Acid) Does Not Exhibit Mutagenic Activity In Vivo
}

\author{
Nora Apsel $^{1}$, Elisa Ruiu ${ }^{2}$ and Krishna Moorthi Bhat ${ }^{*}, 1,2$ \\ ${ }^{I}$ Department of Neuroscience and Cell Biology, University of Texas Medical Branch School of Medicine, Galveston, \\ Texas 77555, USA \\ ${ }^{2}$ Department of Neurology, University of Cagliari, Monserato, Sardenia, Italy
}

\begin{abstract}
Vitamin C (ascorbic acid) is an important antioxidant and there is a wide spread supplementation of diets with vitamin $\mathrm{C}$ among the general population in the form of tablets or powder. Vitamin $\mathrm{C}$ is also present in multi-vitamin tablets along with $\mathrm{Zn}$ and other transitional metal ions. Recent reports, however, have suggested that vitamin $\mathrm{C}$ exhibits pro-oxidant properties and in vitro it can produce genotoxins. Furthermore, a combination of vitamin $\mathrm{C}$ and transitional metal ions had an additive effect in in vitro studies. These results raise the possibility of mutagenic toxicity for vitamin $\mathrm{C}$ with or without the transitional metal ions. We performed a genetic screen to test if vitamin $\mathrm{C}$ can cause mutations in vivo using the model organism Drosophila. We report that a combination of vitamin $\mathrm{C}$ and $\mathrm{Zn}$ had no mutagenic activity in vivo in Drosophila. Additionally, we describe a simple screen using Drosophila to test mutagenic activity of any compound.
\end{abstract}

Keywords: Drosophila, vitamin C, antioxidant, prooxidant.

\section{INTRODUCTION}

Vitamin $\mathrm{C}$ is widely considered as an important antioxidant and its use in general population is widespread, either in the form of tablets or powder, or in combination with other vitamins and $\mathrm{Zn}$ and other transitional metal ions. As an antioxidant, vitamin $\mathrm{C}$ reacts with free radicals produced during oxidative reactions, averting oxidative stress and oxidative damage to cell molecules such as proteins, lipids and DNA [1-3]. Regular supplements of vitamin $\mathrm{C}$ have been suggested as a preventive measure against a variety of diseases and illnesses from cardiovascular disease to the common cold, although there is no definitive evidence proving a direct link between vitamin $\mathrm{C}$ and the prevention of any disease other than scurvy [3]. Recent reports, however, have suggested that vitamin $\mathrm{C}$ exhibits pro-oxidant properties $[2,4]$ and in vitro vitamin $\mathrm{C}$ can produce genotoxins [5]. A combination of vitamin $\mathrm{C}$ and transitional metal ions had an additive effect in in vitro studies [5]. Other factors that appear to determine if vitamin $\mathrm{C}$ acts as a pro-oxidant or an anti-oxidant include the time in which vitamin $\mathrm{C}$ added to biological system and the concentration of vitamin $\mathrm{C}$ added to the system [1]. A subsequent paper, however, indicated that vitamin $\mathrm{C}$ had no significant genotoxicity in a wing spot test using Drosophila [6]. However, this study also found that co-treatments with $\mathrm{CoCl} 2$ and vitamin $\mathrm{C}$ showed a significant increase in the frequency of mutant clones compared to $\mathrm{CoCl} 2$ alone [6]. This result suggests that vitamin $\mathrm{C}$ can also be genotoxic in conjunction with cobalt. However, no proper genetic screens have been conducted to determine if vitamin $\mathrm{C}$ indeed can cause mutations in vivo.

*Address correspondence to this author at the Department of Neuroscience and Cell Biology, University of Texas Medical Branch School of Medicine, Galveston, Texas 77555, USA; Tel: 409-747-2214; Fax: 409-747-2187;

E-mail:kmbhat@utmb.edu
Previously, Podmore et al. [4] reported that Vitamin C exhibits pro-oxidant properties [4]. They examined the prooxidant effect of vitamin $\mathrm{C}$ in vivo by measuring the level of 8-Oxoguanine and 8-Oxoadenine of volunteers taking vitamin C supplements [4]. 8-Oxoguanine and 8-Oxoadenine are mutagenic by-products of DNA oxidation; once incorporated into a gene they cannot be translated and hence produce mutations in genes. Their work showed that there is an increase in 8-Oxoadenine levels and a decrease in 8Oxoguanine levels in volunteers who ingested $500 \mathrm{mg}$ of vitamin $\mathrm{C}$ daily for up to 12 weeks.

Further studies have shown that vitamin $\mathrm{C}$ triggers lipid hydroperoxide conversion to bifunctional electrophiles which develop into genotoxins and cause DNA mutations [2]. Since these findings show vitamin C's pro-oxidant nature in vivo without the addition of transitional metals, it brings into question vitamin C's preventive effect on disease, but it does not demonstrate any harmful effect vitamin $\mathrm{C}$ has in vivo.

Given the above conflicting data on vitamin $\mathrm{C}$, we sought to determine if the genotoxins produced by vitamin $\mathrm{C}$ can cause mutations in vivo using the model system Drosophila. We designed a genetic screen based on an eye-color assay and examined the mutagenic properties of vitamin $\mathrm{C}$, either by itself or in combination with transitional metal ions. Our results show that vitamin $\mathrm{C}$, with and without transitional metal ions, does not have a mutagenic effect in vivo. From these findings we conclude that vitamin C's pro-oxidant effects, including the possible effects of any genotoxins it produces, are compensated by its anti-oxidant effects. Whether or not vitamin $\mathrm{C}$ has substantial health benefits (besides curing scurvy) it requires large double blind studies in human trials over an extended period of time. Our results indicate that consumption of vitamin $\mathrm{C}$ is safe and it is unlikely to cause any mutations. 


\section{MATERIALS AND METHODS}

Genetic stocks: For mutagenizing, newly isogenized wild type Canton $\mathrm{S}$ flies were used. We also used attached XX females for crossing the mutagenized (or treated) males (see results section) in order to assay for any mutagenic activity in an F1 generation itself.

Vitamin C treatment: Two days old Canton S wild type males were starved for $12 \mathrm{hrs}$ and then fed with vitamin $\mathrm{C}$ and zinc chloride $(\mathrm{ZnCl} 2)$ in $1 \%$ sucrose solution for $12 \mathrm{hrs}$. We used three different regimens of vitamin $\mathrm{C}$ and $\mathrm{ZnCl} 2: 1$ ) $100 \mathrm{mM}$ vitamin $\mathrm{C}$ and $2 \mathrm{uM} \mathrm{ZnCl2}$, 2) $125 \mathrm{mM}$ vitamin $\mathrm{C}$ and $2 \mathrm{uM} \mathrm{ZnCl2}$, and 3) $125 \mathrm{mM}$ vitamin $\mathrm{C}$ and $4 \mathrm{uM}$ $\mathrm{ZnCl} 2$. These flies were allowed to recover for $\sim 4 \mathrm{hrs}$ and then mated with attached XX virgin females en masse for 2 days, transferred to new bottles and allowed to lay eggs for another two days before discarding both males and females. The male progeny were then examined for any mutations in the eye-color gene white. A loss of function mutation in this gene should give male progeny that have white-eye or mosaic patches of white pigments in the eye (see results section). We screened a total of about 86,500 male progeny for mutations in the white gene.

Ethyl methanesulfonate mutagenesis: As positive control, we similarly mutagenized males with Ethyl methanesulfonate (EMS) at a concentration of $25 \mathrm{mM}$ in $1 \%$ sucrose solution containing $4 \mathrm{mM} \mathrm{ZnCl} 2$ for 12 hours (see above) and scored for the mutation in the white gene.

Sucrose treatment: As negative control, we used 1\% sucrose with $4 \mathrm{uM} \mathrm{ZnCl} 2$. The treatment and scoring was done as above.

\section{RESULTS AND DISCUSSION}

While the recent reports have suggested that vitamin $\mathrm{C}$ exhibits pro-oxidant properties [2, 4] and in vitro vitamin $\mathrm{C}$ can produce genotoxins [5], a cause for alarm, epidemiological data do not necessarily indicate any apparent mutagenic or genotoxin effect of vitamin $\mathrm{C}$. However, given pro-oxidant properties of vitamin $\mathrm{C}$, we sought to determine if vitamin $\mathrm{C}$ can cause mutations in the model organism, Drosophila melanogaster. A previous study in Drosophila had shown that vitamin $\mathrm{C}$ tested at three different concentrations $(25,75$ and $250 \mathrm{mM})$ showed no significant increase in the frequency of mutant clones generated in a wing spot test [6]. At the same time, this study also found that co-treatments with $\mathrm{CoCl} 2$ and vitamin $\mathrm{C}$ showed a significant increase in the frequency of mutant clones compared to $\mathrm{CoCl} 2$ alone [6]. Given these conflicting results, it is important to know if vitamin $\mathrm{C}$ can indeed cause mutations in vivo. However, no proper genetic screens have been conducted to determine if vitamin $\mathrm{C}$ can indeed generate germline mutations. A proper genetic screen would also eliminate any caveats that may be present in such methods of assays as the wing spot test. Drosophila has been extensively used to generate germline mutations by X-ray or chemicals such as EMS and the mutagenesis regimens such as duration of feeding, etc., has been well-established in this organism.

We targeted the $\mathrm{X}$-chromosome to test the mutagenic activity of vitamin $C$. Since females have two $X$ chromosomes and males have only one, a non-Mendelian segregation of $\mathrm{X}$ chromosome from a mutagenized male would be hemizygous for the mutation and thus, would show a phenotype in adults if the mutation was viable. Since such a non-Mendelian segregation of $\mathrm{X}$ can be achieved using attached $\mathrm{X}$ chromosomes (attached XXs will segregate together, thus, the inheritance of these XXs will be nonMendelian and only by females), we designed a simple strategy for the screen (Fig. 1). In this scheme, we tested if a combination of vitamin $\mathrm{C}$ and $\mathrm{Zn}$ induces any mutations in the eye-color gene white. Even a complete loss of function mutation in the white gene produce viable and normal flies except that their eyes will be white instead of dark red. Since the gene is X-linked, the non-Mendelian segregation of the "mutagenized" male X-chromosome will be hemizygous, thus, a mutation induced in the white gene will be expressed in the next generation. The use of the white gene in this scheme will also allow identification of mosaic F1 mutants in the event that vitamin $\mathrm{C}$ affects only one strand of the DNA in the post-meiotic sperm.

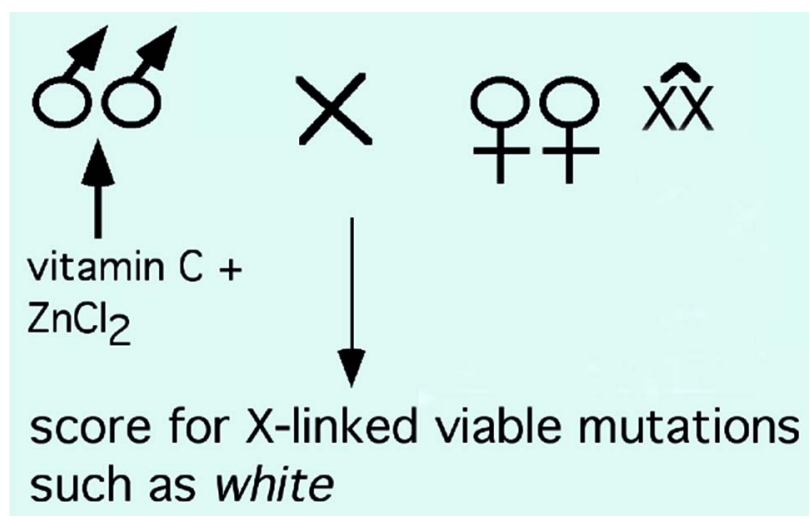

Fig. (1). The scheme for the screen. Two days old Canton S wild type males were starved for $12 \mathrm{hrs}$ and then fed with vitamin $\mathrm{C}$ and $\mathrm{ZnCl}_{2}$ in $1 \%$ sucrose solution for $12 \mathrm{hrs}$. These flies were allowed to recover for $\sim 4 \mathrm{hrs}$ and then mated with attached $\mathrm{XX}$ virgin females en masse for 2 days, transferred to new bottles and allowed to lay eggs for another two days before discarding. The male progeny were then examined for any mutations in the eye-color gene white. A loss of function mutation in this gene should give male progeny that have white eyes or mosaic patches of white pigments in the eye.

We used 3 different concentrations of vitamin $\mathrm{C}$ and $\mathrm{ZnCl} 2$ in our screen (see Table 1). In the first, we used a 100 $\mathrm{mM}$ vitamin $\mathrm{C}$ and $2 \mathrm{uM} \mathrm{ZnCl} 2$. Feeding flies with this amount of vitamin $\mathrm{C}$ and $\mathrm{ZnCl} 2$ caused $6 \%$ lethality in males in a $12-\mathrm{hr}$ feeding time. This much lethality is comparable to the lethality induced by a $25 \mathrm{mM}$ EMS treatment for $12 \mathrm{hrs}$. In a second experiment, we fed males for a similar duration with $125 \mathrm{mM}$ vitamin $\mathrm{C}$ and $2 \mathrm{uM} \mathrm{ZnCl} 2$. This resulted in $16 \%$ lethality, indicating that doubling the amount of $\mathrm{ZnCl} 2$ significantly increases (nearly 3-fold) the lethality among treated males. In a third experiment, we treated males with $125 \mathrm{mM}$ vitamin $\mathrm{C}$ and $4 \mathrm{uM} \mathrm{ZnCl} 2$. This caused $55 \%$ lethality, indicating that increasing the amount of both causes a very high level of lethality. This increase in lethality indicates that vitamin $\mathrm{C}$ is toxic at high dosage, which could be by altering physiological conditions at the cellular and organismal level. This could also be due to an enhanced oxidative stress. The precise reason for this toxicity is not 
Table 1. Vitamin C Does Not Display Any Mutagenic Activity In Vivo

\begin{tabular}{|c|c|c|c|c|c|}
\hline Trial & $\begin{array}{c}\text { Concentration of } \\
\text { Vitamin C + Zncl }\end{array}$ & $\begin{array}{c}\text { No. of Males } \\
\text { Mutangenized }\end{array}$ & $\begin{array}{c}\text { Lethality in } \\
\text { Treated Males (\%) }\end{array}$ & $\begin{array}{c}\text { Total No. of } \\
\text { Males Scored }\end{array}$ & $\begin{array}{c}\text { No. of X-Linked } \\
\text { Viable Mutations }\end{array}$ \\
\hline \hline 1 & $100 \mathrm{mM}+2 \mu \mathrm{M}$ & 1650 & 6 & 31,000 & 39,000 \\
2 & $125 \mathrm{mM}+2 \mu \mathrm{M}$ & 55 & $\begin{array}{c}\text { None } \\
\text { None } \\
\text { None }\end{array}$ \\
\hline 3 & $125 \mathrm{mM}+4 \mu \mathrm{M}$ & 1650 & 7 & 9,700 & 10 \\
\hline 5 & $25 \mathrm{mM} \mathrm{EMS}$ & 400 & 0.5 & 16,500 & None \\
\hline
\end{tabular}

A similar treatment of males with $25 \mathrm{mM}$ EMS causes about $7 \%$ lethality and induces mutations in the white at a frequency of about $1 / 1000$ chromosomes, which served as a positive control. A similar treatment of males with $1 \%$ sucrose solution together with $4 \mathrm{mM} \mathrm{ZnCl} 2$ causes $\sim 0.5 \%$ lethality and does not induce any mutations.

clear at the moment. At the same time, this result suggests that we have reached the maximum dosage that can be tolerated by this organism and if there is any genotoxicity, we should be able to observe it.

As shown in Table 1, the remaining treated males produced progeny and in each experiment we scored a large number of males. A total of over 86,500 males were screened for any mutation in the white gene. We also scored these flies for any other dominant mutations (such as curled or notched wing, etc) that vitamin $\mathrm{C}$ might have induced. However, we did not find any mutations in the white gene or any other dominant viable mutations in any of the 3 treatment regimens (Table 1). These results are consistent with the previous finding that vitamin $\mathrm{C}$ did not enhance the frequency of mutant clones generated in a wing spot test using Drosophila. In a comparable experiment where EMS is used to generate mutations in the white gene, we observed a frequency of 1 mutation per 1000 chromosomes screened (Table 1). The number of progeny that we have examined among vitamin $\mathrm{C}$ treated males is 85 times more than this and we believe that this is a reasonable number to determine if a combination of vitamin $\mathrm{C}$ and $\mathrm{Zn}$ would cause mutations in vivo.

Our results show that vitamin $\mathrm{C}$, with or without $\mathrm{Zn}$, a transitional metal, has no mutagenic effect in Drosophila. However, we note that vitamin $\mathrm{C}$ together with cobalt enhanced the frequency of mutant clones compared to cobalt alone [6], although it is not clear if cobalt can cause germline mutations either alone or in combination with vitamin $\mathrm{C}$. Using this same assay system, it has been also reported that vitamin $\mathrm{C}$ reduces genotoxicity of potassium dichromate [6]. Moreover, protective effects of vitamin $\mathrm{C}$ against genotoxicity induced by radiation [7], or alkylating agent such as N-ethyl-N-nitrosourea (ENU) [8] or insecticide [9] have been reported using in vivo animal models. On the other hand, it is still possible that vitamin $\mathrm{C}$ might not be a mutagen in flies but in humans. The argument against this possibility is that large doses of vitamin $\mathrm{C}$ are widely used by humans and there is no epidemiological indication that this causes cancer and other diseases as one might expect for a mutagen [10, 11]. Moreover, it has been shown that supplementation of vitamin $\mathrm{C}$ causes elevated levels of 8 Oxoadenine, however, this treatment also reduces the levels of 8-Oxaguanine [4], both are markers for DNA damage induced by oxidants, thus, balancing out the pro with antioxidants. Given that 8-Oxoguanine is believed to be 10 times more mutagenic than 8 -Oxoadenine [1], it would seem that the decrease in 8-Oxoguanine is in fact more significant than the increase in 8-Oxoadenine. The current study shows that in Drosophila, treatment with a combination of high doses of vitamin $\mathrm{C}$ and $\mathrm{Zn}$ has no harmful mutagenic effect in vivo. Although a direct comparison between Drosophila and humans is not possible, taken together with the epidemiological studies that indicate relative safety of vitamin $\mathrm{C}$ supplementation among humans $[10,11]$, the demonstration that vitamin $\mathrm{C}$ lacks mutagenic activity in vivo in Drosophila is further reassuring. Additionally, our screen can be generally used to determine mutagenic activity of any compound in vivo.

\section{ACKNOWLEDGEMENTS}

We would like to thank all the members of the Bhat lab for discussion and help, and members of the Neurology group at the University of Cagliari. KB likes to thank Prof. Francesco Marrosu, Chair, Neurology Department at the University of Cagliari, for hosting his sabbatical at the University of Cagliari. This work was supported by a grant from the National Institutes of Health (NIGMS-NIH) to KB.

\section{REFERENCES}

[1] Carr A, Frei B. Does Vitamin C act as a pro-oxidant under physiological conditions? FASEB J 1999; 13: 1007-25.

[2] Lee SH, Oe T, Blair IA. Vitamin C-induced decomposition of lipidhydroperoxides to endogenous genotoxins. Science 2001; 292: 2083-6.

[3] Sebastian JP, Katz A, Wang Y, et al. Vitamin C as an antioxidant: evaluation of its role in disease prevention. J Am Coll Nutr 2003; 22: 18-35.

[4] Podmore ID, Griffiths HR, Herbert KE, Mistry N, Mistry P, Lunec J. Vitamin C exhibits pro-oxidant properties. Nature 1998; 392: 559 .

[5] Buettner GR, Jurkiewicz BA. Catalytic metals, ascorbate and free radicals: combinations to avoid. Radiat Res 1996; 145: 532.

[6] Kaya B, Creus A, Velazquez A, Yanikoglu A, Marcos R. Genotoxicity is modulated by ascorbic acid. Studies using the wing spot test in Drosophila. Mutat Res 2002; 520: 93-101.

[7] Roy LD, Mazumdar M, Giri S. Effects of low dose radiation and vitamin $\mathrm{C}$ treatment on chloroquine-induced genotoxicity in mice. Environ Mol Mutagen 2008; 49: 488- 95.

[8] Aidoo A, Lyn-Cook LE, Lensing S, Wamer W. Ascorbic acid (vitamin C) modulates the mutagenic effects produced by an alkylating agent in vivo. Environ Mol Mutagen 1994; 24: 220-8. 
[9] Assayed ME, Khalaf AA, Salem HA. Protective effects of garlic extract and vitamin $\mathrm{C}$ against in vivo cypermethrin-induced cytogenetic damage in rat bone-marrow. Mutat Res 2010; 702:1-7.

[10] Morton DJ, Barrett-Connor EL, Schneider DL. Vitamin C supplements use and bone mineral density in postmenopausal women. J Bone Min Res 2001; 16: 135-40.
[11] Enstron J, Kanim LE, Klein MA. Vitamin C intake and mortality among a sample of the United States population. Epidemiology 1992; 3: 194-202.

Received: June 22, 2011

Revised: July 21, 2011

Accepted: July 21, 2011

(C) Apsel et al.; Licensee Bentham Open.

This is an open access article licensed under the terms of the Creative Commons Attribution Non-Commercial License (http://creativecommons.org/licenses/by-nc/ $3.0 /$ ) which permits unrestricted, non-commercial use, distribution and reproduction in any medium, provided the work is properly cited 